\title{
Correction to: Apocynin and dimethyl sulfoxide synergistically protect against ischemia-reperfusion injury in a rat hind limb ischemia-reperfusion model
}

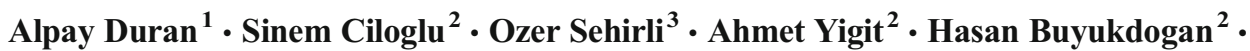 \\ Aslı Duran ${ }^{4} \cdot$ Kubra Elcioğlu $^{5} \cdot$ Levent Kabasakal $^{5}$
}

Published online: 9 November 2017

(C) Springer-Verlag GmbH Germany 2017

Correction to: Eur J Plast Surg (2017)

https://doi.org/10.1007/s00238-017-1309-8

Dr. Ozer Sehirli's affiliation needs to be updated as he was transferred from Marmara University Faculty of Pharmacy to Near East University Faculty of Dentistry two years ago. The updated information is provided in the affiliation section below.

The online version of the original article can be found at https://oi.org/ $10.1007 / \mathrm{s} 00238-017-1309-8$

Alpay Duran

dr.alpayduran@hotmail.com

1 Department of Plastic, Reconstructive and Aesthetic Surgery, Sanliurfa Mehmet Akif Inan Training and Research Hospital, Sanliurfa, Turkey

2 Department of Plastic, Reconstructive and Aesthetic Surgery, Haydarpasa Numune Training and Research Hospital, Istanbul, Turkey

3 Near East University, Faculty of Dentisty, Near East Boulevard, Nicosia / TRNC, 99138 Mersin 10, Turkey

4 Department of Dermatology, Sanliurfa Balikligol State Hospital, Sanliurfa, Turkey

5 Department of Pharmacology, School of Pharmacy, Marmara University, Istanbul, Turkey 